\title{
Utilização de métodos geofísicos elétricos no estudo de célula experimental de aterro sanitário
}

\author{
Helio Ohmaye ${ }^{1^{\star}}$, Vagner Roberto Elis ${ }^{1}$, Nataly Marcela Aranda Camacho ${ }^{1^{*}}$, Miriam Gonçalves Miguel ${ }^{2}$ \\ ${ }^{1}$ Departamento de Geofísica. Instituto de Astronomia, Geofísica e Ciências Atmosféricas USP \\ ${ }^{2}$ Faculdade de Engenharia Civil, Arquitetura e Urbanismo UNICAMP
}

Copyright 2016, SBGf - Sociedade Brasileira de Geofísica

Este texto foi preparado para a apresentação no VII Simpósio Brasileiro de Geofísica, Ouro Preto, 25 a 27 de outubro de 2016. Seu conteúdo foi revisado pelo Comitê Técnico do VII SimBGt, mas não necessariamente representa a opinião da SBGf ou de seus associados. É proibida a reprodução total ou parcial deste material para propósitos comerciais sem prévia autorização da SBGt.

\section{Abstract}

Geoelectrical methods are essential tools for investigating urban solid waste landfills. In order to identify and characterize the waterproofing infrastructure of the area and the body waste, resistivity and induced polarization were used in an experimental cell set up according to existing principles of engineering landfill, located in Campinas city, State of Sao Paulo and monitored by University of Campinas UNICAMP. The collected data were processed using the software RES2DINV. The results indicate the efficiency of the electrical resistivity method to identify the geometry of the cell and of the structures with resistive and conductive anomalies as well as to interpret the cell dynamic behavior.

\section{Introdução}

A técnica de disposição de resíduos sólidos urbanos RSU em aterros sanitários consiste no confinamento na menor área e no menor volume possível formando camadas superpostas, usando o perfil natural do solo.

O monitoramento do comportamento estrutural dos aterros sanitários está relacionado a parâmetros geomecânicos, como permeabilidade, compressibilidade, resistência mecânica do material componente, degradação da matéria orgânica, avaliação das deformações, recalques e prevenção de rupturas e/ou vazamentos, fundamentais para estimativa de sua vida útil.

Neste trabalho, a Geofísica se insere como técnica para auxiliar o gerenciamento de aterro sanitário, verificando as condições da infra-estrutura básica de impermeabilização. Os métodos utilizados são eletrorresistividade e polarização induzida para obtenção de informações de forma eficiente, rápida, sem danos físicos na infra-estrutura e agressão ao meio ambiente. Os dados coletados foram realizados em período de 2 anos, sempre durante a estação seca - inverno.

\section{Área de estudo e Metodologia}

A célula experimental está localizada no aterro sanitário Delta $A$ e ocupa uma área de $5080 \mathrm{~m}^{2}$. (Figura 1). A impermeabilização da base da célula é composta por uma camada de solo argiloso compactado com 0,5 $\mathrm{m}$ de espessura, uma manta de Polietileno de Alta Densidade com 1,5 mm para impedir a percolação de líquidos lixiviados no solo, e um geotêxtil não tecido, para a proteção mecânica da manta. Sobre o geotêxtil foi colocada uma camada de silte areno-siltoso com 0,1 $m$ de espessura para a proteção termo-mecânica. Foram executados os taludes laterais para a compactação do RSU e contenção do líquido lixiviado, e uma canaleta central de drenagem para o lixiviado, com $0,3 \mathrm{~m}$ de profundidade e $2 \mathrm{~m}$ de largura. A camada final de cobertura é constituída por solo argiloso compactado com $0,5 \mathrm{~m}$ de espessura.
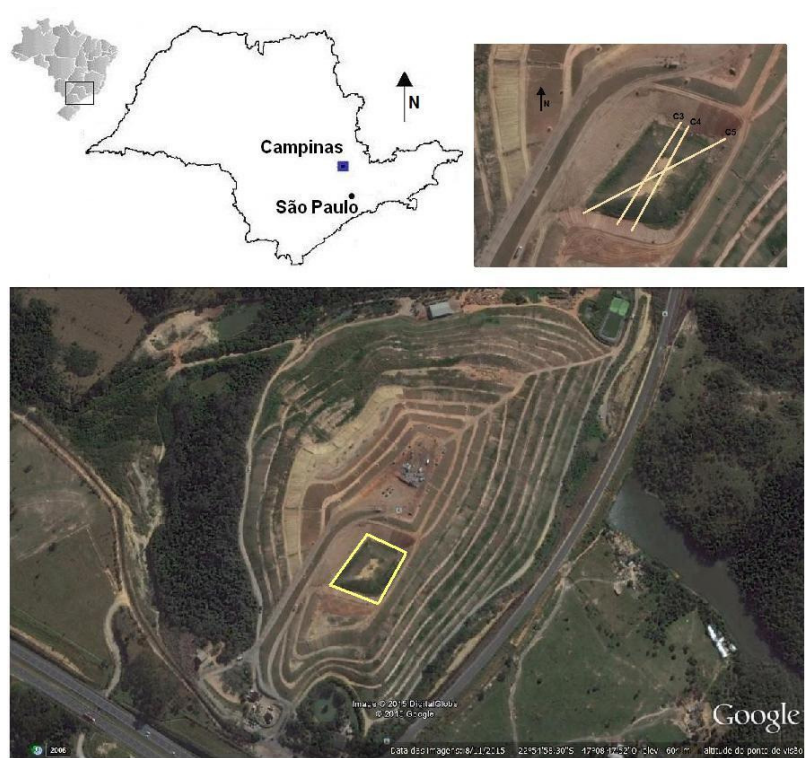

Figura 1 - Localização esquemática do aterro sanitário Delta A, próximo a Rodovia dos Bandeirantes, com destaque para a célula experimental no topo do aterro, com as linhas de perfil realizadas com o arranjo dipolodipolo, espaçamento entre eletrodos de $5 \mathrm{~m}$ para as linhas C3 e C4, e de 2,5 m para a C5.

A eletrorresistividade é um método geofísico que utiliza uma corrente elétrica artificial introduzida no terreno através de dois eletrodos, para medir o potencial gerado em outros dois eletrodos nas proximidades do fluxo de corrente, permitindo calcular a resistividade real ou aparente em subsuperfície (Elis, 2005). O parâmetro físico resistividade é a resistência dos materiais em conduzir a corrente elétrica e, para solos e rochas, dependem da porosidade, teor de água, 
composição mineralógica e natureza dos sais dissolvidos - Equação 1:

$$
\rho=K \frac{\Delta V}{I}
$$

onde $\boldsymbol{K}$ é um fator geométrico que depende somente de distancias entre os eletrodos de corrente e de potencial. Os trabalhos de coleta de dados realizados na célula experimental utilizam o caminhamento elétrico - CE, arranjo dipolo-dipolo, onde os eletrodos de corrente formam um dipolo alinhado com os de potencial, sobre uma mesma linha de perfil. O espaçamento entre todos os pares de eletrodos é mantido constante.

Outro método utilizado foi a polarização induzida. Quando a corrente contínua utilizada pelo medidor de resistividade no arranjo de quatro eletrodos é desligada, a voltagem entre os eletrodos de potencial não cai a zero de modo instantâneo, sofrendo um decaimento gradual e pode levar alguns segundos para atingir o valor nulo. Fenômeno semelhante é observado quando a corrente é ligada (Kearey et al, 2002). A subsuperfície age como um capacitor, armazenando carga elétrica, e é utilizado para localização de zonas onde estão disseminados os materiais condutivos. $O$ parâmetro físico medido na polarização induzida é a cargabilidade - Equação 2:

$$
M=\frac{1}{\Delta V_{P}} \int_{t_{1}}^{t_{2}} \Delta V_{I P}(t) d t
$$

\section{Resultados}

Os valores de resistividade e cargabilidade aparente são obtidos no mesmo equipamento, resistivímetro Syscal Pro acoplado a uma bateria externa, e as leituras de potencial são coletadas por eletrodos porosos não polarizáveis. São apresentadas três linhas de investigação, todas com 0 arranjo dipolo-dipolo, espaçamento entre eletrodos de $5 \mathrm{~m}$ (linhas C3 e C4) e de 2,5 $\mathrm{m}$ (linha C5). As medidas de resistividade e de cargabilidade foram processadas e interpretadas com 0 software RES2DInv (Loke, 2002). O programa utiliza processo de inversão para determinar um modelo de resistividade para a subsuperfície, cuja melhor resposta concorde com os valores medidos. Como os valores medidos são de resistividade aparente, o programa altera o modelo inicial de modo iterativo para minimizar as diferenças entre as respostas do modelo e os valores medidos. O resultado final apresenta zonas com diferentes valores de resistividade, relacionadas com o objeto de estudo - geomembrana - como profundidade do terreno e existência de elementos líquidos contaminantes.

Os dados de medição de campo obtidos com o caminhamento elétrico, processados com o RES2DInv, fornecem as seções de resistividade, considerando as opções de parametrização de inversão com vínculo de suavização, inversão robusta e de refinamento. A Figura 2 apresenta os resultados para a linha C3, onde é possível identificar a geomembrana - alta resistividade, em relação à sua base horizontal, e o corpo de chorume - alta condutividade, no interior dos resíduos e na extensão da base.
A linha $\mathrm{C} 4$, praticamente paralela à linha $\mathrm{C} 3$, apresenta - mesmo contraste de resistividade para a geomembrana na base horizontal da célula, e uma concentração de chorume no interior dos resíduos, em sua parte direita. (Figura 3 ).

A Figura 4 apresenta os resultados para a linha de aquisição C5, onde é possível observar o formato trapezoidal da célula experimental tendo a geomembrana como "moldura", a depressão na parte central da seção e o acúmulo do chorume no interior dos resíduos, sobre a camada de geomembrana. A explicação para a depressão central é a existência da canaleta para escoamento do chorume, líquido contaminante recolhido para evitar a percolação no subsolo e possível contaminação do meio físico. A Figura 5 apresenta o detalhe da canaleta e a linha de perfil de aquisição $\mathrm{C} 5$, em posição quase paralela à canaleta.

Os dados de polarização induzida - IP foram coletados juntamente com os de resistividade, processados com o RES2DInv, e fornecem as seções de cargabilidade. Os valores de cargabilidade para os resíduos devem ser mais altos que os do entorno, devido à presença de materiais metálicos e outros materiais polarizáveis no interior da célula. Por outro lado, possíveis bolsões de chorume devem apresentar baixa cargabilidade devido a alta salinidade (grande concentração de íons no chorume). A Figura 6 apresenta os resultados para a linha C3, considerando as opções de inversão, sem identificação do corpo de resíduos, da geomembrana e da pluma de chorume.

A seção de cargabilidade para a linha de aquisição C4 é apresentada na Figura 7, onde é possível identificar uma provável zona com concentração de chorume no lado direito e na parte central, correspondente a canaleta de escoamento do líquido.

A seção de cargabilidade para a linha de aquisição C5 é apresentada na Figura 8, onde é possível identificar uma zona de concentração de chorume (material polarizável) no lado direito e na parte central, nas depressões da canaleta de escoamento do líquido.

\section{Discussão e Conclusões}

O objetivo de identificação e caracterização da célula experimental de resíduos sólidos urbanos com a aplicação de métodos geoelétricos foi alcançado, após a interpretação dos dados adquiridos nos ensaios realizados.

Os procedimentos de caminhamento elétrico e de polarização induzida fornecem seções com parâmetros distintos - resistividade e cargabilidade - que se complementam na interpretação dos dados adquiridos.

A utilização dos métodos de inversão no RES2DInv permite localizar a infra-estrutura impermeabilizante, através dos valores de resistividade mais elevados, com as opções de inversão com vínculo robusto e de refinamento de modelo. As zonas contendo líquido contaminante, valores de resistividade mais baixos, podem ser identificadas com clareza nas seções de resistividade, algumas vezes comprovadas nas de cargabilidade.

A utilização adequada dos métodos de investigação geoelétrica permite a visualização de áreas contendo líquido contaminante no interior do corpo de resíduos, 
através do contraste nos valores obtidos com os ensaios.

\section{Agradecimentos}

Os autores gostariam de agradecer a Faculdade de Engenharia Civil, Arquitetura e Urbanismo, Universidade Estadual de Campinas, pelo apoio na realização dos trabalhos de aquisição dos dados.
Elis, V. R, 2005. A geofísica como ferramenta para detectar e mapear contaminação. IAG - Escola de Verão.

Kearey, P., Brroks, M. \& Hill, I., 2002. Geofísica de Exploração. Oficina de Textos.

Loke, M.H. - 2002 - RES2DINV ver. 3.4 - 2D resistivity and IP inversion. Penang: M.H. Loke Software User's Manual.

\section{Referências}
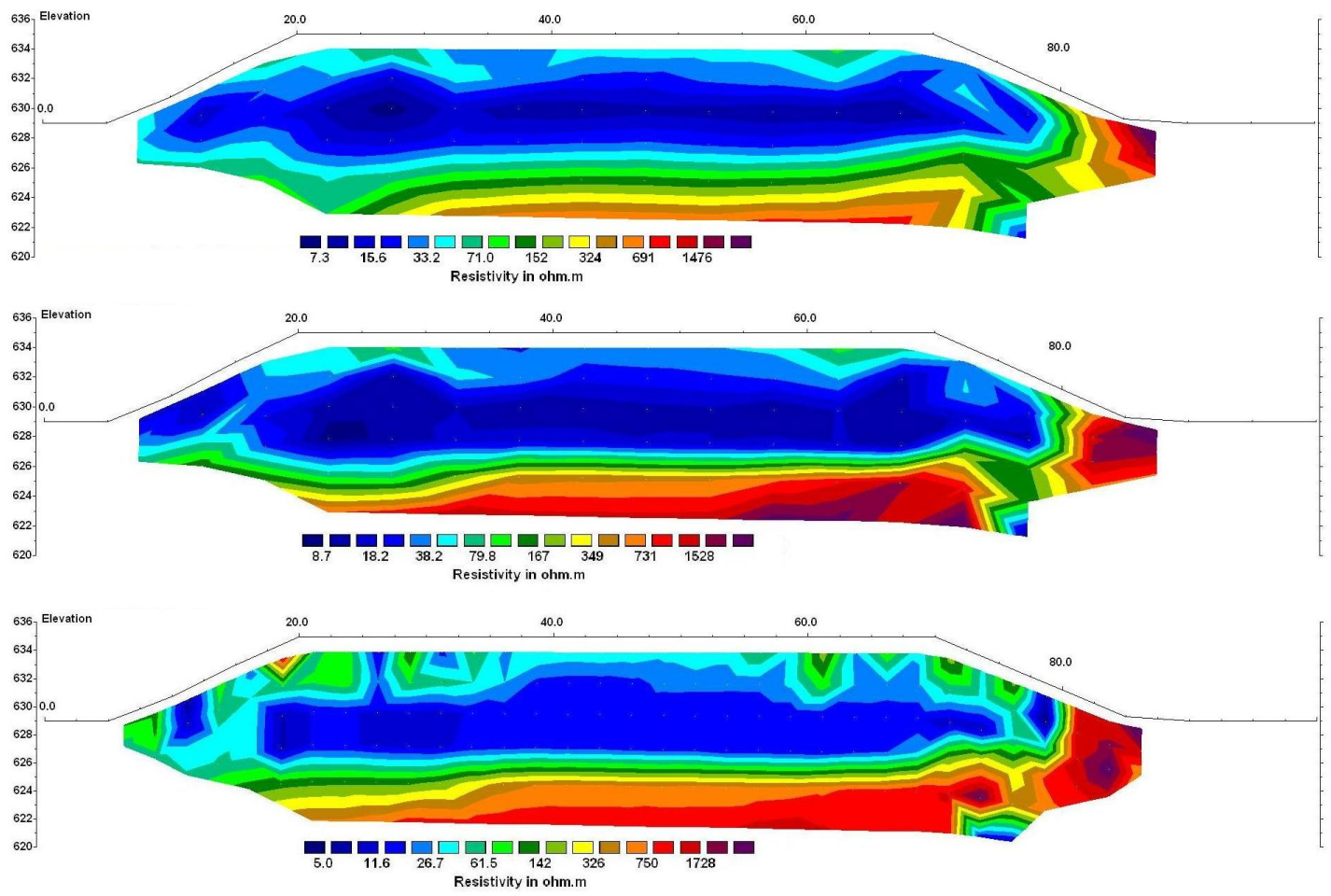

Figura 2 - Perfil de resistividade aparente, linha C3, considerando as opções de inversão com vínculo de suavização, robusto e de refinamento, respectivamente 

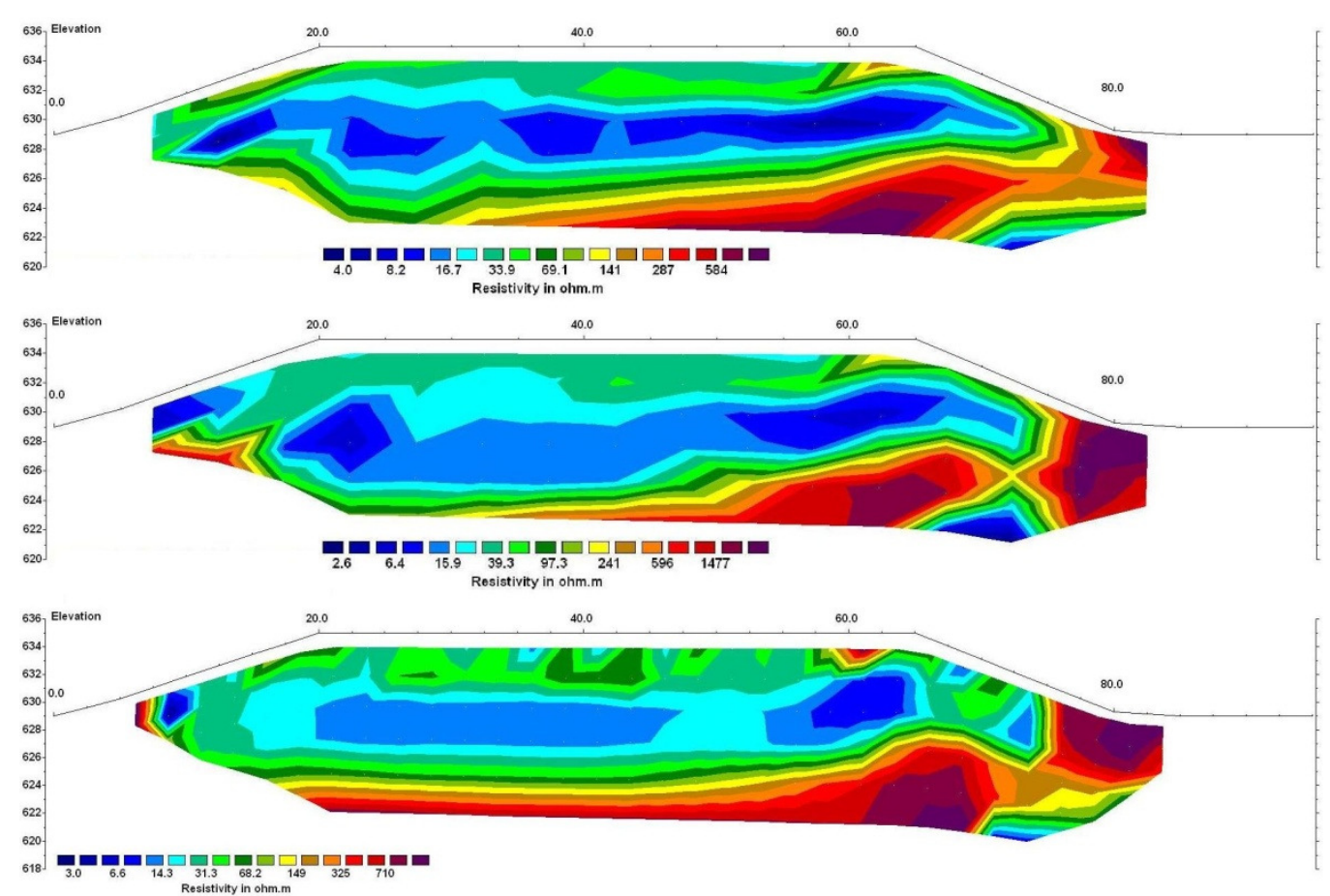

Figura 3 - Perfil de resistividade aparente, linha C4, considerando as opções de inversão com vínculo de suavização, robusto e de refinamento, respectivamente.
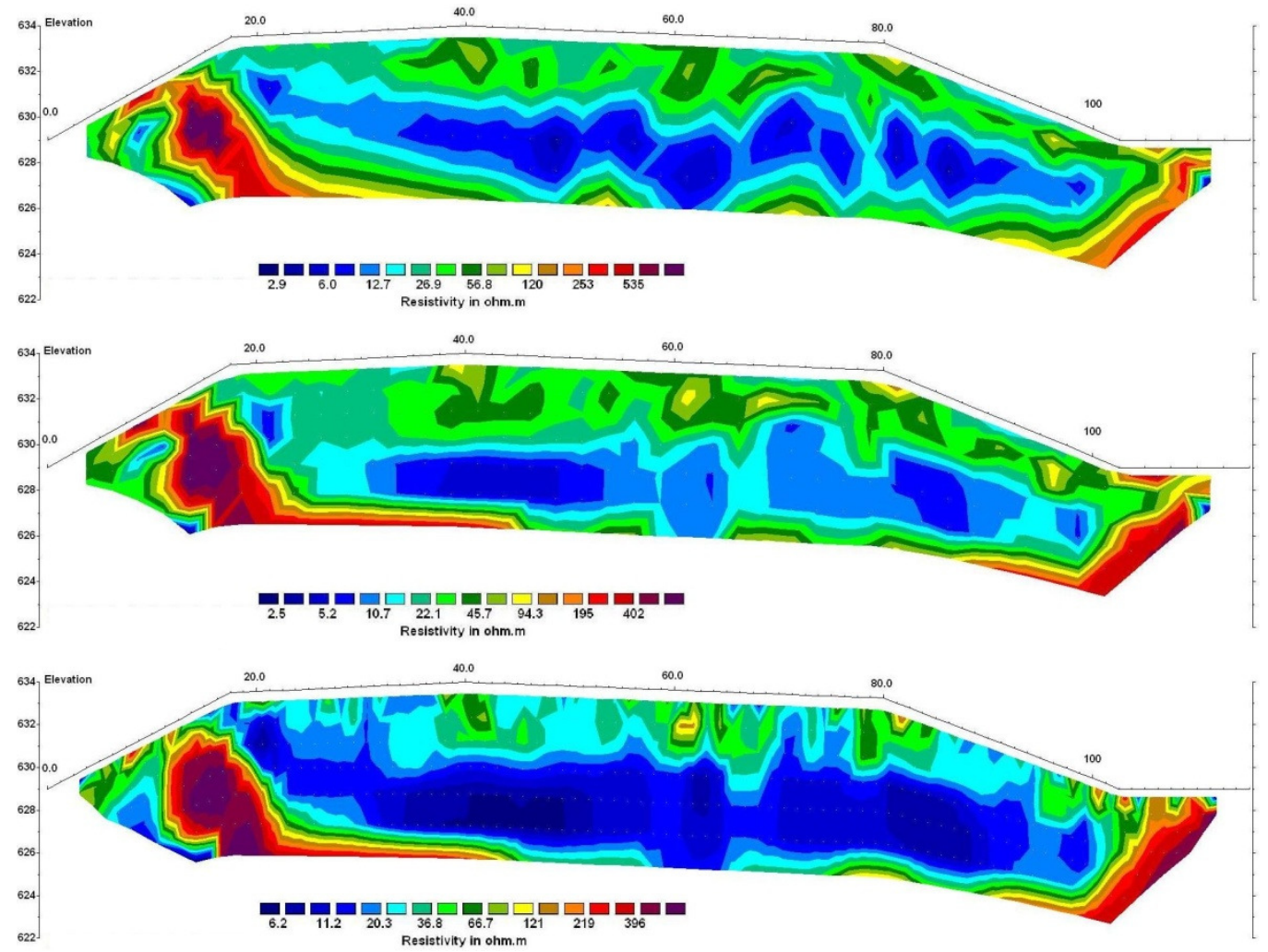

Figura 4 - Perfil de resistividade aparente, linha C5, considerando as opções de inversão com vínculo de suavização, robusto e de refinamento, respectivamente. 


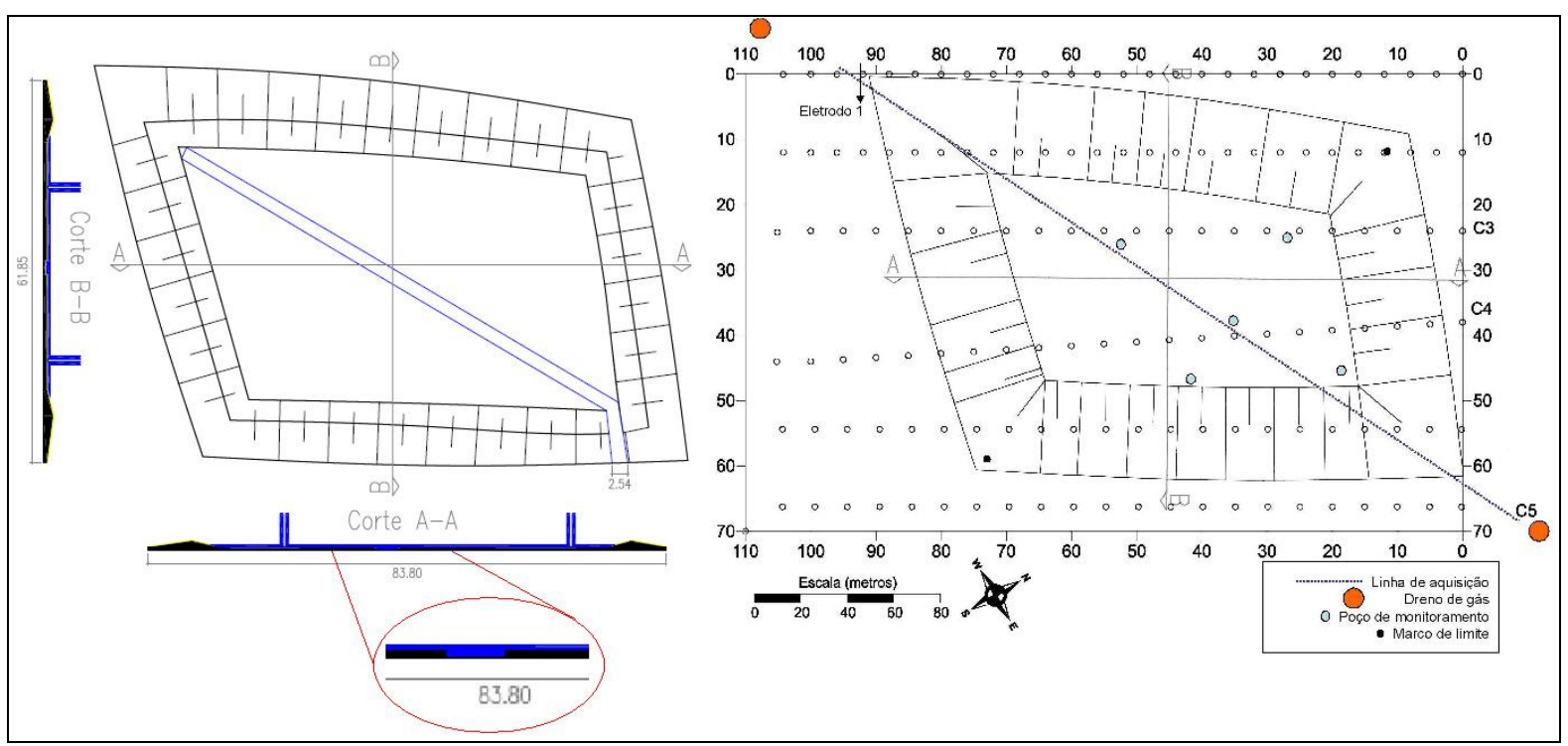

Figura 5 - Detalhe da canaleta para escoamento do chorume e linha de aquisição C5.
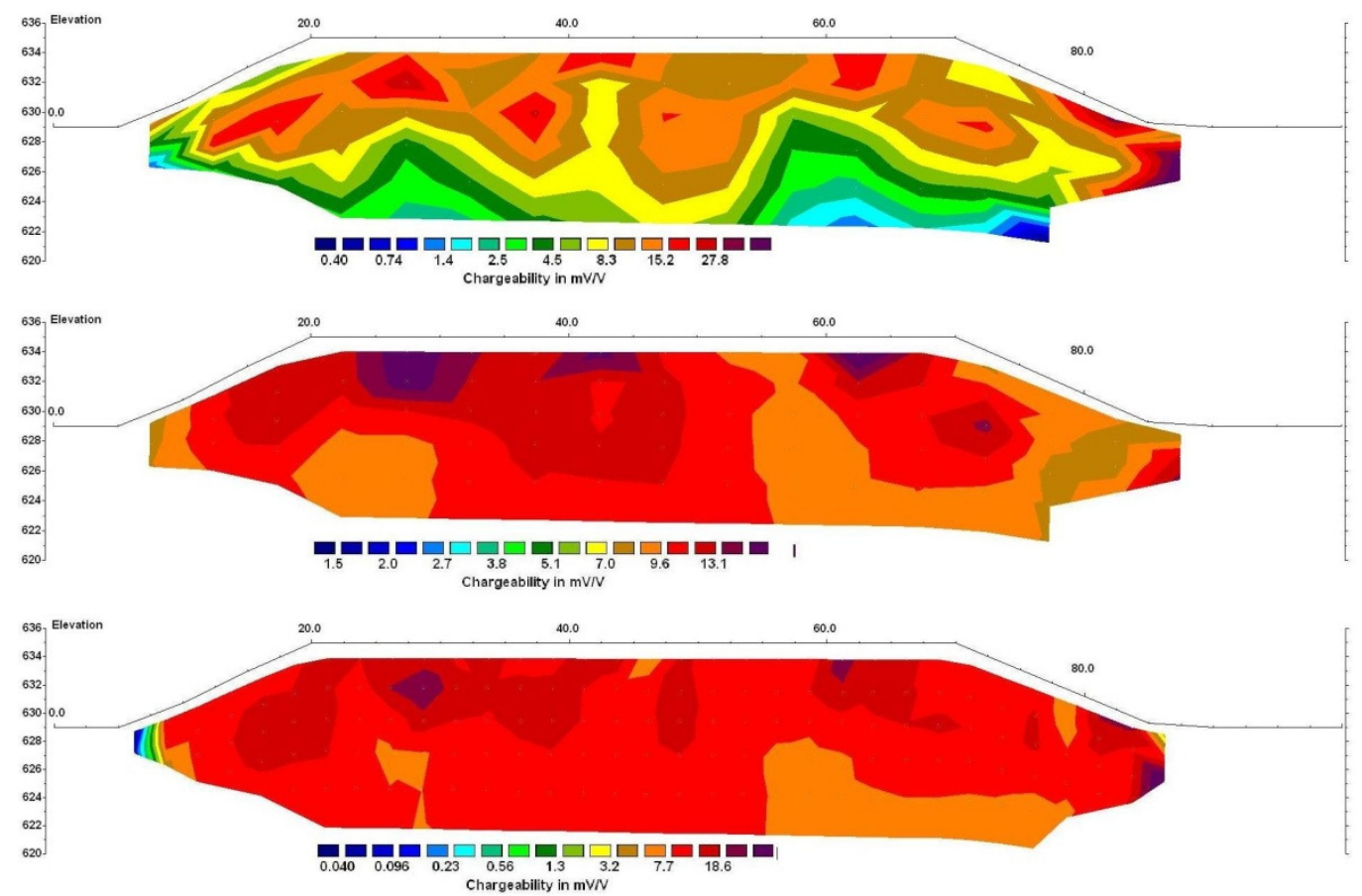

Figura 6 - Perfil de cargabilidade, linha C3, considerando as opções de inversão com vínculo de suavização, robusto e de refinamento, respectivamente. 

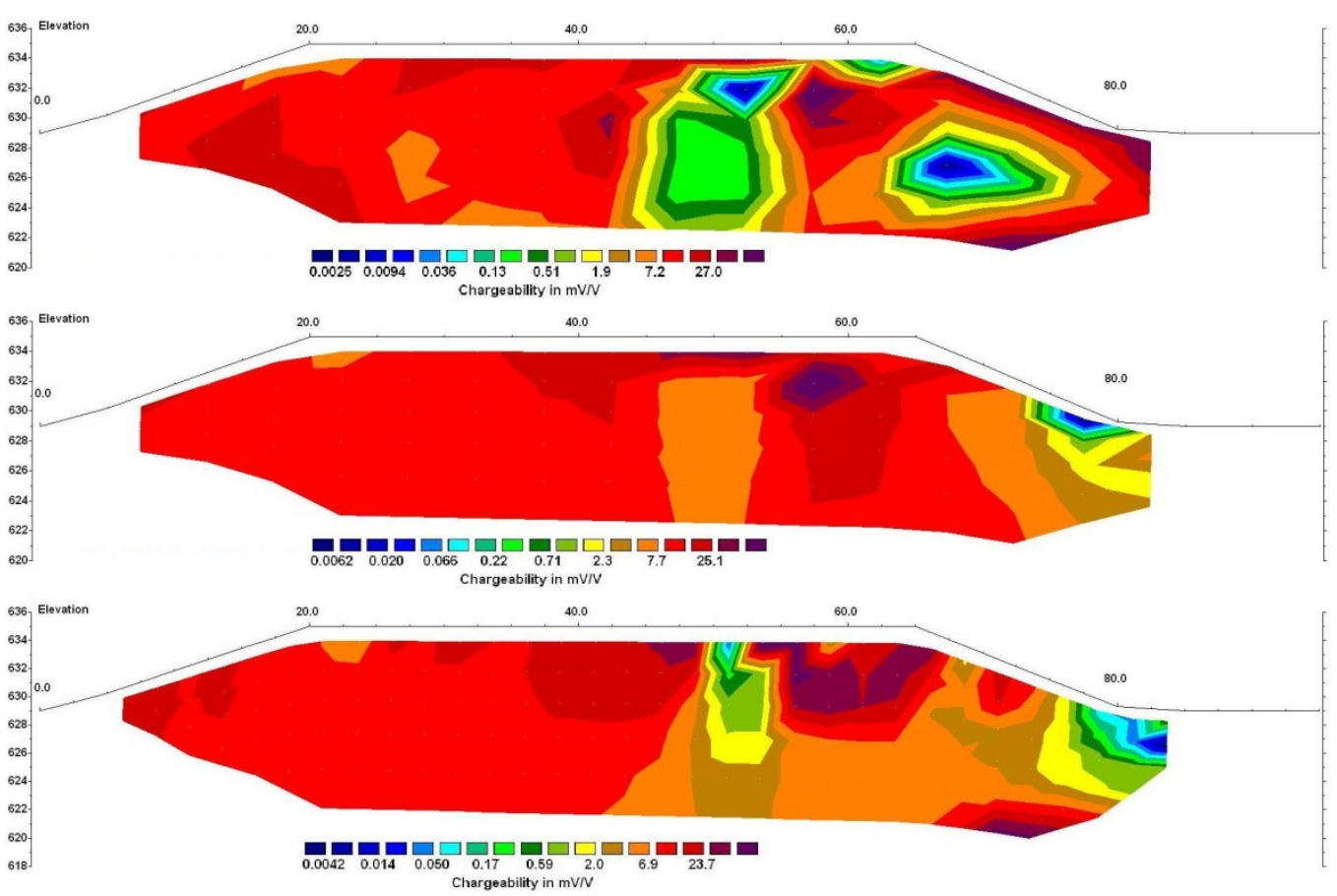

Figura 7 - Perfil de cargabilidade, linha C4, considerando as opções de inversão com vínculo de suavização, robusto e de refinamento, respectivamente.
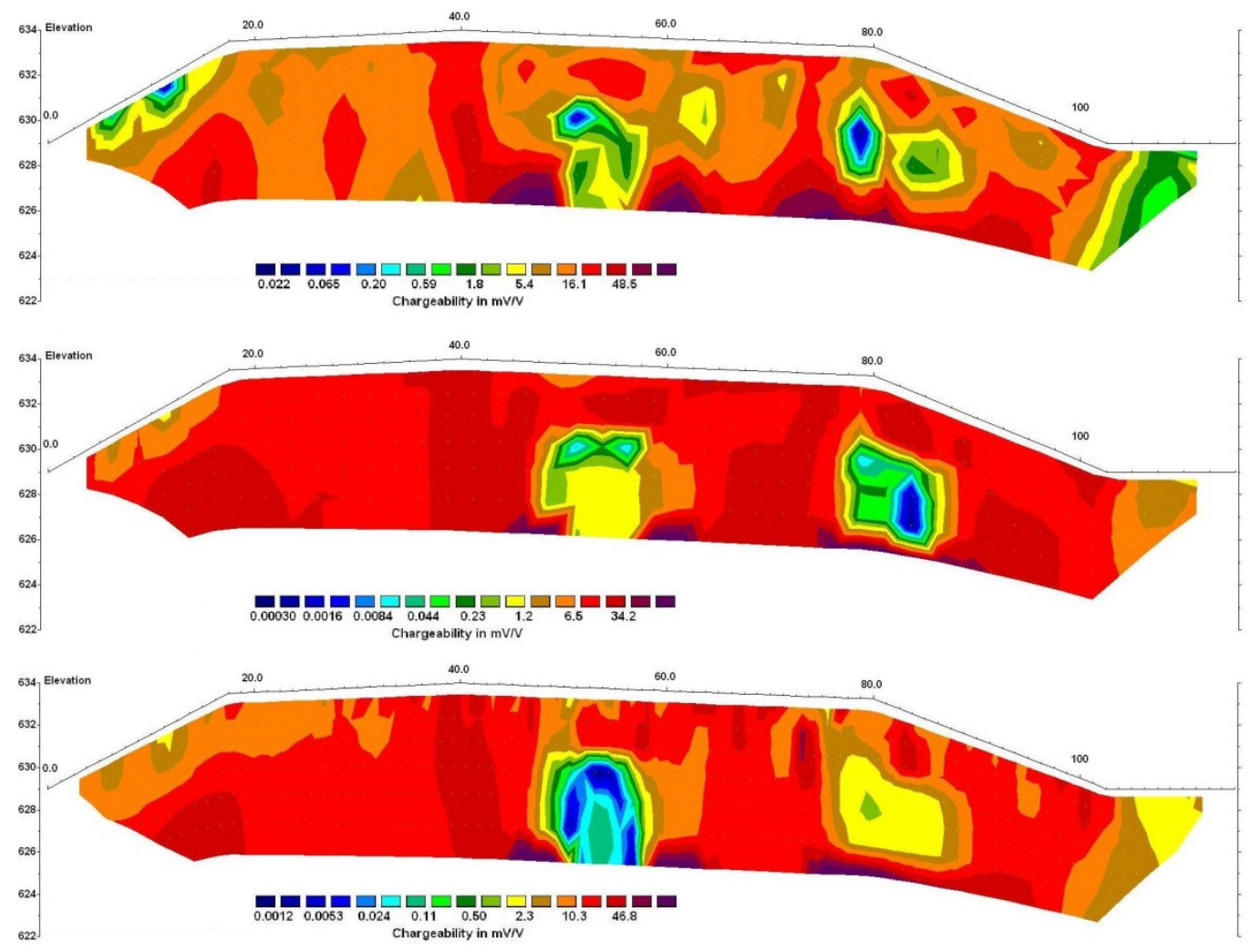

Figura 8 - Perfil de cargabilidade, linha C5, considerando as opções de inversão com vínculo de suavização, robusto e de refinamento, respectivamente. 